\title{
Economic Analysis of a Fuelwood Consuming Activity: Empirical Evidence for Traditional Red Sorghum Beer Producers in Ouagadougou, Burkina Faso
}

\author{
Boukary Ouédraogo ${ }^{1} \&$ Patrick Point ${ }^{2}$ \\ ${ }^{1}$ Université Ouaga2, Burkina Faso \\ ${ }^{2}$ Université Montesquieu Bordeaux IV, France \\ Correspondance: Boukary Ouédraogo, Université Ouaga, 04 BP 8938 Ouagadougou 04, Burkina Faso. Tel: \\ 226-7882-8132. E-mail: boukary_ouedraogo2003@yahoo.fr
}

\author{
Received: September 10, 2014 Accepted: September 15, 2014 Online Published: March 8, 2015 \\ doi:10.5539/eer.v5n1p1 \\ URL: http://dx.doi.org/10.5539/eer.v5n1p1
}

\begin{abstract}
This paper aims to analyze the determinants of input demand for local red sorghum beer production in Ouagadougou, which is an activity conducted mainly by women from these areas. The descriptive analysis in the paper emphasizes on the extent of this activity in the national economy, and namely in firewood consumption. The producer theory approach through an econometrical method using a cost translog function also helps to derive conditional input demand namely for firewood. The estimated coefficients of firewood conditional demand of local beer producers, "dolotières", have shown weak price elasticity hampering the fuelwood price policy. However, the simulation regarding taxation of fuelwood price effect on quantity demanded consequently states an overall reduction in demand for fuelwood in Ouagadougou. This induces a decrease in the local beer producer's profit for a given level of production. In addition, the paper deals with short term analyses.
\end{abstract}

Keywords: Translog Cost Function, return to scale, dolo supply, elasticities, red sorghum beer, producer's surplus, firewood demand

\section{Introduction}

Most studies on the demand for wood energy in developing countries are referred to as household demand. Several authors have studied the determinants of household energy choices and the transition between wood energy and other conventional sources of energy: Hosier (1988), Ferari (1990), Hosier and Dowd (1997), Ouedraogo (2002; 2006), and Fawelinmi Oyerinde (2002), Campbell et al (2003). Some authors were also interested in describing wood energy sector and quantifying the volume and value of timber produced on certain markets (Chavin, 1981; Sow, 1990; Banks et al., 1996; Alam et al., 1998).

These studies have either emphasized the scale of the problems of urban and rural households' wood energy supply, or analyzed the relationship between the demand for wood energy and income levels of households. They have also described the difficulties to substitute other energy sources to firewood and have contributed to the evaluation of the determinants of household energy choices.

This attention to consumption of wood for domestic use obscures the usage of wood in crafts. However, it is clear that the majority of artisans in Sub Saharan Africa uses wood energy as input in their production, so that today, due to growth of certain craft activities (various foundries, forges, jewelry, traditional brewery, restaurant etc.), this demand especially in urban areas, far exceeds domestic demand. In Ouagadougou, the aggregate demand of wood energy in 2000 is shared by $59 \%$ as intermediate consumption for artisans and $41 \%$ as household consumption. The five major categories of artisans whose demand for fuelwood is very marked in this city are the bronze foundries, aluminum smelters, restaurant owners, barbecue and local red sorghum beer producers namely "dolotières".

In the foregoing contribution (of artisan usage of firewood), it is the "dolotières" who catch our attention. They produce "dolo", a traditional beer made from red sorghum. This activity is conducted by more than 1,000 of women in Ouagadougou. Dolo preparation requires two days of cooking and uses an average of $458.17 \mathrm{~kg}$ of firewood, that is, about a half ton of wood. In 2000, wood consumption for the production of dolo amounted to 
48,269 tons, representing $28 \%$ of craftsmen's total consumption and $16.5 \%$ of wood total consumption. Note that this activity generates significant revenue for very vulnerable social strata. Since the devaluation of the CFA franc in January 1994 in West African Economic and Monetary Union (WAEMU) countries, higher prices for industrial beer resulted in increased dolo demand, which induces an increase in the production of this traditional beer and an increase in the number of production units.

As it is difficult to conduct effective policies for firewood substitution by other sources (of energy) for households mainly due to the heterogeneity in this population, public interventions on a production sector such as dolo production which is relatively homogeneous could be easier and more effective to design and implement.

The objective of this work is to bring together elements of an economic analysis in order to provide better insight into the possibilities to limit firewood consumption in a sector that heavily relies on it.

After delivering pieces of information on the processing and marketing of dolo, we will econometrically estimate the function of total production cost, and we analyze the properties of production technology. We will then go through an aggregate approach of supply function for the city of Ouagadougou. The results obtained will allow us to outline effective policies to reduce wood consumption in this activity.

\section{Notes on Dolo Production and Data Set}

We consider the description given by Marie-Michele Ouedraogo (1974, p. 284). "Red Sorghum purchased on the market or in the countryside, is put to germinate, [and] then dried up before being crushed. Thus, it is quenched in large jars half stuck in the ground. The mixture is stirred and bailed out, and transferred into cooking jars put on wood fireplaces. After a first cooking of about three hours, a new transfer occurs in the jars stuck in the ground, where the mixture cools for hours. A second cooking of seven or eight hours completes the preparation of dolo. We then have a sweet non-alcoholic juice called "Biss-Kom" or water of germinated red sorghum. From that moment, the dolo is drinkable, but it is never marketed at this stage. The liquid is again cooled in jars stuck in the ground and then fermented for a long time with a handful amount of sourdough incorporated by the "dolotière". In Ouagadougou, plants of all kinds can be introduced into the dolo at that moment to activate fermentation and spice dolo taste. Dolo must be kept the night of the second day of preparation and the morning of the third day it is ready [for consumption] ..." So is summarized the process of making this traditional beer that lasts about ten hours of preparation.

Women who produce red sorghum beer are called "dolotières". Dolo has a very important cultural value and occurs largely in the tradition of the Burkinabe people (customary rites and festivals). It is also a highly priced drink in both urban and rural areas. The CFA franc's devaluation in January 1994 and the country's fiscal policy regarding taxation of alcoholic beverage greatly contributed to raising the price of industrial beer. As a consequence, demand for traditional beer has increased, resulting in new entry of "dolotières" in the dolo industry and in increasing the number of producers. "Dolotières" are present in all districts and neighborhoods of Ouagadougou, though it should be noted that their density is higher in the suburbs (newly parceled and non-parceled areas).

The data used in this study were collected in 2000 during extensive surveys on "craftsmen woodfuel demand in Ouagadougou". These surveys were funded by the Coordination Unit of the Regional Program of Traditional Energy Sector (UC-RPTES). A specific questionnaire was developed for "dolotières". Of 1013 dolotières located in Ouagadougou, 154 were interviewed during the survey, that is, $15 \%$ of these producers. Table 1 provides details of key economic data listed.

Table 1. Key economic variables collected on "dolotières"

\begin{tabular}{ll}
\hline Variables & Units \\
\hline Production of « Dolo » & Liter « Dolo » or value in CFA Franc \\
Price of « Dolo » & CFA F/Liter \\
Cost of red sorghum (ferment) & CFA F/Kilogram \\
Price of red sorghum & CFA F/Kilogram \\
Firewood cost & CFA F/Kilogram \\
Firewood price & CFA F/Kilogram \\
Water cost & CFA F/Liter \\
Water price & CFA F/Kilogram \\
Wage / production & CFA F/Employee/production (cooking) \\
Firewood quantity & Kilogram \\
\hline
\end{tabular}


Water quantity Liter

Red sorghum ferment quantity Kilogram

Source: RPTES (2000).

It should be noted that this information relates mainly variable costs. This leads us to confine ourselves to a short term approach, without direct consideration of fixed costs. These data will be used to develop a total restricted variable cost function. We will use a flexible functional form: the translog.

\section{A Translog Model of Total Dolo Production Costs}

The non-homothetic translog function is a second order Taylor series of the logarithm of the cost with respect to the logarithm of the explanatory variables. It gives an approximation of an unknown function a priori and imposes relatively few restrictions on production technology. We can add that cost shared equations derived are linear in parameters. Unlike homothetic functions, conditional demands for input are function of production level. Given its properties, it is the most common functional form used to specify cost functions (Note 1) nowadays.

\subsection{Model Functional Specification}

The non-homothetic Translog Cost Function is written as follows:

$$
\ln C=\ln \alpha_{0}+\sum_{i=1}^{n} \alpha_{i} \ln P_{i}+\frac{1}{2} \cdot \sum_{i=1}^{n} \sum_{j=1}^{n} \gamma_{i j} \ln P_{i} \ln P_{j}+\alpha_{y} \ln Y+\frac{1}{2} \gamma_{y y}(\ln Y)^{2}+\sum_{i=1}^{n} \gamma_{i y} \ln P_{i} \ln Y
$$

where $\gamma_{i j}=\gamma_{j i}$,

$i, j=$ firewood (B), germinated red sorghum (M), labor $(L)$ and water $(E)$; $C$ is the total cost of production, Pi the price of the $\mathrm{i}^{\text {th }}$ input, $\mathrm{Y}$ the quantity of dolo produced.

Factor prices and production levels are exogenous variables. $\alpha$ and $\gamma$ are parameters to be estimated (Note 2).

In order to adequately describe producer's behavior, cost function must be, among other things, homogeneous of degree 1 with respect to prices of inputs used, for a given level of production. This implies the following restrictions:

$$
\sum_{i=1}^{n} \alpha_{i}=1, \quad \sum_{i=1}^{n} \gamma_{i j}=\sum_{i=1}^{n} \gamma_{j i}=\sum_{i=1}^{n} \gamma_{i Y}=0
$$

Other restrictions inherent to Translog Cost Function could be added:

- For this cost function to be homothetic, it is necessary and sufficient that the parameters $\gamma_{i Y}=0 \forall i=1, \ldots ., n$. Homogeneity of constant degree with production function takes place if in addition to the foregoing restrictions on homotheticity, we set: $\gamma_{Y Y}=0$; in which case the degree of homogeneity is equal to $1 / \alpha_{Y}$.

- The constant returns to scale of dual production function will appear if, in addition to the restrictions of homotheticity and homogeneity, $\alpha_{Y}=1$. Finally, translog function reduces to Cobb-Douglas function with constant returns to scale if, besides all the above-mentioned limitations, we require that each of $\gamma_{i j}=0, i, j=1, \ldots, n$.

\subsection{Estimation Procedure}

The Translog Cost Function can be directly estimated from equation (1), but for more efficient estimators, it can be achieved by estimating the optimum demand equations of factors resulting from cost minimization, transformed here into cost shares of factors equations (E. R. Berndt, 1991). Thus, by deriving the equation (1) and using Shephard's lemma, we obtain the following cost shares of factors equations: 


$$
\frac{\partial \ln C}{\partial \ln P_{i}}=\frac{P_{i}}{C} \frac{\partial C}{\partial P_{i}}=\frac{P_{i} X_{i}}{C}=\alpha_{i}+\sum_{j=1}^{n} \gamma_{i j} \ln P_{j}+\gamma_{i Y} \ln Y
$$

where $\sum_{i=1}^{1} P_{i} X_{i}=C$, total cost of factors.

The cost shares of factors $\mathrm{S}_{\mathrm{i}}$, are defined as follows:

$$
S_{i} \equiv P_{i} X_{i} / C \text {, et } \sum_{i=1}^{n} S_{i}=1 .
$$

For this study, "dolotières" use four factors of production. So, factor demand equations or cost shares of factor equations will be as follows in the system of equations (4):

$$
S_{i}=\alpha_{i}+\sum_{j=1}^{n} \gamma_{i j} \ln P_{j}+\gamma_{i Y} \ln Y \quad, \quad i=1,2, . ., 4
$$

Note that without symmetry restrictions there are 24 parameters to be estimated, six in each of four cost shares equations. If the constraints of symmetry between the four equations are imposed $\left(\gamma_{12}=\gamma_{21}, \gamma_{13}=\gamma_{31}, \gamma_{14}=\gamma_{41}, \gamma_{23}=\gamma_{32}, \gamma_{24}=\gamma_{42}\right.$, and $\left.\gamma_{34}=\gamma_{43}\right)$, the number of parameters to be estimated is reduced to 18. As previously posed in equation (2), economic theory requires that the Translog Cost Function be homogeneous of degree 1 with respect to factor prices: the inclusion of this constraint results in the following restrictions in the group of equations (5):

$$
\sum_{i=1}^{4} \alpha_{i}=1, \quad \sum_{i=1}^{4} \gamma_{i Y}=0, \quad \sum_{j=1}^{4} \gamma_{i j}=0, \quad i=\{1,2,3,4\}
$$

These six restrictions will further reduce the number of parameters to estimate from 18 to 12 . The system of equations of factors' demand has the special property that for each observation, the sum of the dependent variables (the share of cost) of all equations is always equal to one. Indeed, if there are $n$ units of factor cost (or factor demand equations), only n-1 are linearly independent. This property of factor demand equations has several econometric implications on which we will focus our attention.

First, since the sum of cost shares is always equal to unity and only $n-1$ of factor demand equations are linearly independent, then system (5) relations imply that the sum of Ordinary Least Squares (OLS) residuals $u_{i}$ across all factor demand equations is always equal to 0 for each observation:

$\sum_{i=1}^{4} u_{i}=0$, and errors matrix $\mathrm{A} *$ is singular and non-diagonal.

Second, because of the unit amount of cost shares of factors for each observation, when symmetry restrictions are not imposed, estimation equation by equation using least squares (OLS) method gives parameters that always obey property of homogeneity in the system of equations (5). Berndt and Wood (1975.1979) have empirically shown that the parameters estimated by OLS, when the constraint of symmetry among the demand for factors equations is not imposed, still obey the restrictions of the system (5). However, the cross product of OLS residues matrix is not singular. Thus, OLS method produces good estimators.

Third, the fact that the covariance and errors cross-product matrices must both be singular, the estimation by the method of maximum likelihood, which minimizes the cross product of errors, is not feasible. Also, the procedure most commonly used to solve matrix singularity problem is to eliminate arbitrary one of the $\mathrm{n}$ demand equations and proceed to the estimation of the $\mathrm{n}-1$ remaining equations by the ML method. In this case, we will eliminate the fourth equation and directly estimate, equation by equation, the 12 parameters of the three equations shown in system (6):

$$
\begin{aligned}
& S_{1}=\alpha_{1}+\gamma_{11} \ln \left(P_{1} / P_{4}\right)+\gamma_{12} \ln \left(P_{2} / P_{4}\right)+\gamma_{13} \ln \left(P_{3} / P_{4}\right)+\gamma_{1 Y} \ln Y \\
& S_{2}=\alpha_{2}+\gamma_{21} \ln \left(P_{1} / P_{4}\right)+\gamma_{22} \ln \left(P_{2} / P_{4}\right)+\gamma_{23} \ln \left(P_{3} / P_{4}\right)+\gamma_{2 Y} \ln Y \\
& { }_{3}=\alpha_{3}+\gamma_{31} \ln \left(P_{1} / P_{4}\right)+\gamma_{32} \ln \left(P_{2} / P_{4}\right)+\gamma_{33} \ln \left(P_{3} / P_{4}\right)+\gamma_{3 Y} \ln Y
\end{aligned}
$$

Eliminated equation parameters are deduced indirectly from restrictions tied to the property of homogeneity in system (5), which allows them to be written in terms of estimated parameters of the first three equations. These 
parameters are expressed as follows:

$$
\begin{aligned}
& \alpha_{4}=1-\left(\alpha_{1}+\alpha_{2}+\alpha_{3}\right) \\
& \gamma_{14}=-\left(\gamma_{11}+\gamma_{12}+\gamma_{13}\right) \\
& \gamma_{24}=-\left(\gamma_{12}+\gamma_{22}+\gamma_{23}\right) \\
& \gamma_{34}=-\left(\gamma_{13}+\gamma_{23}+\gamma_{33}\right) \\
& \gamma_{4 Y}=-\left(\gamma_{1 Y}+\gamma_{2 Y}+\gamma_{3 Y}\right) \\
& \gamma_{44}=-\left(\gamma_{14}+\gamma_{24}+\gamma_{34}\right) \Rightarrow \gamma_{44}=\gamma_{11}+\gamma_{22}+\gamma_{33}+2\left(\gamma_{12}+\gamma_{13}+\gamma_{23}\right)
\end{aligned}
$$

Note that the parameters indirectly estimated are linear combinations of parameters estimated directly from the three equations selected. Likewise, variances of these parameters are linear combinations of those of the first equations, which facilitate their computation.

\section{Results and Economic Analysis of Dolo Production}

The sample used includes 149 "dolotières" of the 154 respondents. For the estimation, several methods are used (OLS, 2SLS, 3SLS and ML). We will favor the method of Maximum Likelihood, since it not only gives invariant parameters, but also provides statistics that directly help test our hypotheses.

\begin{tabular}{|c|c|c|c|}
\hline \multicolumn{4}{|c|}{ Translog Cost Function } \\
\hline Variables & Parameters & Variables & Parameters \\
\hline$\alpha(0)$ & $10,942(616,9)^{* * *}$ & $\gamma(\mathrm{LY})$ & $-0,027(-2,5)^{* *}$ \\
\hline$\alpha(\mathrm{B})$ & $0,312(45,0)^{* * *}$ & $\alpha(\mathrm{B})$ & $0,312(45,0)^{* * *}$ \\
\hline$\alpha(\mathrm{M})$ & $0,583(89,6)^{* * *}$ & $\gamma(\mathrm{BB})$ & $0,134(5,0)^{* * *}$ \\
\hline$\alpha(\mathrm{E})$ & $0,053(23,5)^{* * *}$ & $\gamma(\mathrm{BM})$ & $-0,128(-5,5)^{* * *}$ \\
\hline$\alpha(\mathrm{L})$ & $0,052(0,1)$ & $\gamma(\mathrm{BE})$ & $0,0003(0,0)$ \\
\hline$\gamma(\mathrm{BB})$ & $0,134(5,0)^{* * *}$ & $\gamma(\mathrm{BL})$ & $-0,006(-0,2)$ \\
\hline$\gamma(\mathrm{MM})$ & $0,204(8,5)^{* * *}$ & $\gamma(\mathrm{BY})$ & $-0,039(-5,2)^{* * *}$ \\
\hline$\gamma(\mathrm{EE})$ & $0,035(12,4)^{* * *}$ & $\alpha(\mathrm{M})$ & $0,583(89,6)^{* * *}$ \\
\hline$\gamma(\mathrm{LL})$ & $0,053(1,1)$ & $\gamma(\mathrm{MM})$ & $0,204(8,5)^{* * *}$ \\
\hline$\gamma(\mathrm{BM})$ & $-0,128(-5,5)^{* * *}$ & $\gamma(\mathrm{ME})$ & $-0,032(-5,6)^{* * *}$ \\
\hline$\gamma(\mathrm{BE})$ & $0,0003(0,0)$ & $\gamma(\mathrm{ML})$ & $-0,044(-1,3)$ \\
\hline$\gamma(\mathrm{BL})$ & $-0,006(-0,2)$ & $\gamma(\mathrm{MY})$ & $0,072(10,2)^{* * *}$ \\
\hline$\gamma(\mathrm{ME})$ & $-0,032(-5,6)^{* * *}$ & $\alpha(\mathrm{E})$ & $0,053(23,5)^{* * *}$ \\
\hline$\gamma(\mathrm{ML})$ & $-0,044(-1,3)$ & $\gamma(\mathrm{EE})$ & $0,035(12,4)^{* * *}$ \\
\hline$\gamma(\mathrm{EL})$ & $-0,003(-0,3)$ & $\gamma(\mathrm{EL})$ & $-0,003(-0,3)$ \\
\hline$\alpha(\mathrm{Y})$ & $0,801(39,7)^{* * *}$ & $\gamma(\mathrm{EY})$ & $-0,006(-2,7)^{* * *}$ \\
\hline$\gamma(\mathrm{YY})$ & $-0,064(-2,4)^{* *}$ & $\alpha(\mathrm{L})$ & $0,052(0,1)$ \\
\hline$\gamma(\mathrm{BY})$ & $-0,039(-5,2)^{* * *}$ & $\gamma(\mathrm{LL})$ & $0,053(1,1)$ \\
\hline$\gamma(\mathrm{MY})$ & $0,072(10,2)^{* * *}$ & $\gamma(\mathrm{LY})$ & $-0,027(-2,5)^{* * *}$ \\
\hline$\gamma(\mathrm{EY})$ & $-0,006(-2,7)^{* *}$ & & \\
\hline
\end{tabular}

\subsection{Variable Total Cost Function of Folo Production}

We have simultaneously estimated the demand functions for input and the cost function under the constraints of symmetry, of homothety and of homogeneity.

Table 2. Estimation results by the method IZEF / LM (SUR) of cost shares equations and of the Translog Cost Function. 149 sample observations. T-statistics are in parentheses

\begin{tabular}{llllll}
\hline Statistics & Functions & & & & \\
\cline { 2 - 6 } & Firewood & Red Sorghum & Water & Labor & Log (Variable Cost) \\
\hline $\mathrm{R}^{2}$ & 0,20 & 0,48 & 0,52 & 0,40 & 0,95 \\
Ajusted- ${ }^{2}$ & 0,18 & 0,46 & 0,51 & 0,38 & 0,94 \\
Durbin-Watson & 1,87 & 1,86 & 2,06 & 1,58 & 1,80 \\
Mean dependent var. & 0,33 & 0,57 & 0,05 & 0,06 & 10,61 \\
\hline
\end{tabular}

$\mathrm{B}=$ Firewood, $\mathrm{M}=$ Germinated Red Sorghum (ferment), $\mathrm{L}=$ Labor, $\mathrm{E}=$ Water. 
*** implies that the coefficient is statistically significant at $1 \%$,

** implies that the coefficient is statistically significant at $5 \%$

* implies that the coefficient is statistically significant at $10 \%$.

IZEF/LM = Iterative Seemingly Unrelated Regression

Parameters estimated by IZEF/LM method are consistent with symmetry constraint, and are linearly homogeny to prices.

Graph $n^{\circ} 1$ shows adjustment of cost function to data.

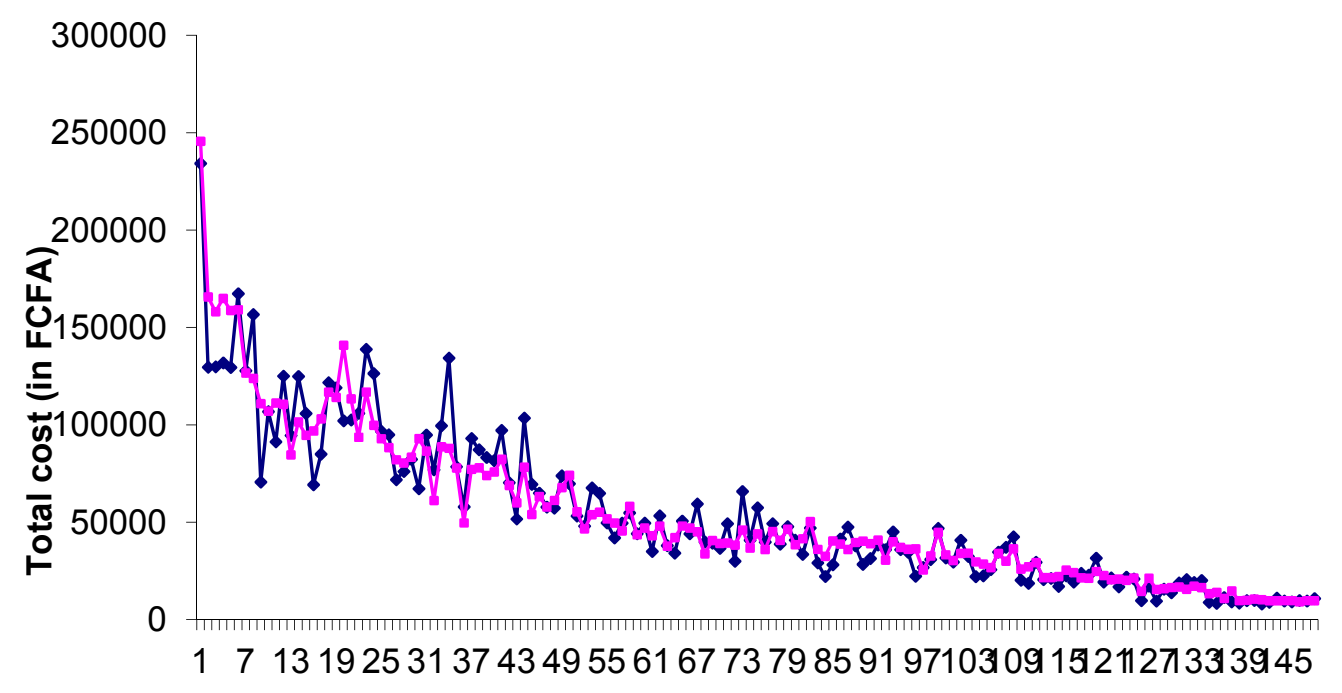

Dolotières

$\longrightarrow$ Total Cost Observed $\longrightarrow$ Total Cost Estimated

Figure 1. Total cost of dolo production

If one focuses on the relationship between quantity produced and total production costs, by setting the variables to their average price, we obtain the line represented by the graph $n^{\circ} 2$

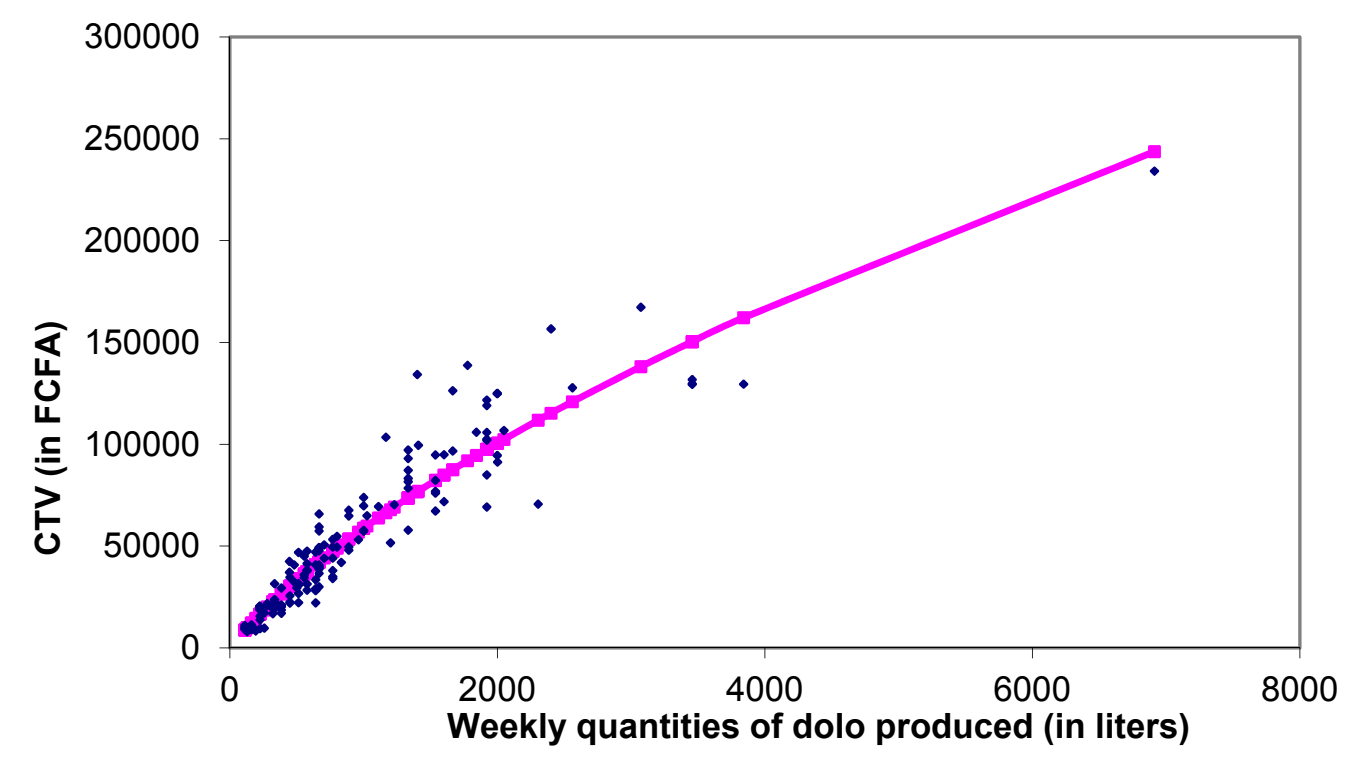

Figure 2. Links between quantities produced of dolo and total cost (setting prices to the sample average) 


\subsection{Economic Analysis of Dolo Production Technology}

\subsubsection{Cost Shares}

Estimation procedure of total cost bases upon the computation of cost shares. These are obtained par the formula (4 bis):

$$
S_{i}=\alpha_{i}+\sum_{j=1}^{n} \gamma_{i j} \ln P_{j}+\gamma_{i Y} \ln Y, \quad i, j=B, M, L, E . \quad \text { (4bis) }
$$

The leading share is from millet, and then wood with respectively on average, $57 \%$ and $32 \%$. The other two factors weigh very little since water is $5 \%$ and wages $1 \%$ of the variable total cost.

Since our focus is on wood consumption, it is interesting to examine the relationship between the share of costs devoted to wood and the level of dolo production. Table 2 shows that the coefficient $\gamma_{\mathrm{BY}}$ is negative. This effect is clearly illustrated on graph 3 which connects the cost shares of wood to production level.

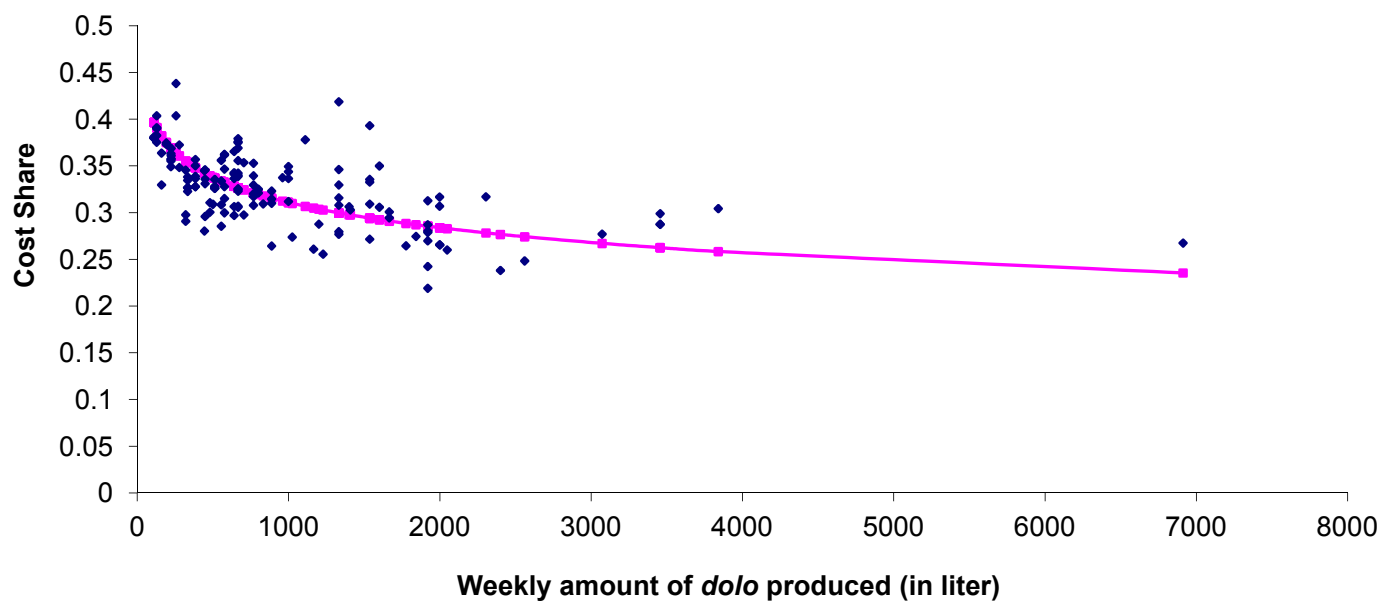

Figure 3. Trend of wood cost share with respect to dolo production

Production is characterized by a decrease of costshare devoted to the factor of production, wood, when the quantities produced increase. This assumes the existence of production technology of increasing returns to scale as indicating an improvement in inputs (firewood) productivity when stepping dolo production.

\subsubsection{Return to Scale}

The whole process seems to present returns to scale. As Giora Hanoch (1975) showed it, returns to scale (presented here by $\mu$ ) are computed as the inverse of elasticities of cost function with regard to production (Note 3) $(\varepsilon C Y)$ :

$$
\mu=1 / \varepsilon C Y, \text { where } \quad \varepsilon C Y=\partial \ln C / \partial \ln Y=\alpha Y+\gamma B Y \ln P B+\gamma M Y \ln P M+\gamma L Y \ln P L+\gamma E Y \ln P E+\gamma Y Y \ln Y
$$

$\varepsilon C Y$ is computed using average prices of factors or by approximating this quantity relative to the average marginal cost and the mean of average costs observed.

Calculation gives the value: $\varepsilon c y=0,801$ and a return to scale: $\mu=1 / \varepsilon c y=1,25$. So, technology shows an increasing return to scale.

\subsubsection{Marginal Cost of Production}

We scrutinize production marginal cost taking into account input prices set to the sample average. To the extent that variable total cost has been estimated by normalizing the variables, terms linked to prices cancel out, and average variable total cost (CTVM) becomes:

$$
C T V M=\frac{e^{\alpha_{0}}}{\bar{Y}^{\alpha_{Y}}} Y^{\alpha_{Y}} e^{\gamma_{Y Y}[\ln (Y)-\ln (\bar{Y})]^{2}}
$$


Thus, marginal cost gives:

$$
C m V M=\frac{\partial C T V M}{\partial Y}=-\frac{e^{\alpha_{0}}}{\bar{Y}^{\alpha_{Y}}}\left[2 \gamma_{Y Y} \ln (\bar{Y})-\alpha_{Y}-2 \gamma_{Y Y} \ln (Y)\right] Y^{\left(\alpha_{Y}-1\right)} e^{\gamma_{Y Y}[\ln (\bar{Y})-\ln (Y)]^{2}}
$$

The following graph 4 shows marginal and average costs curves.

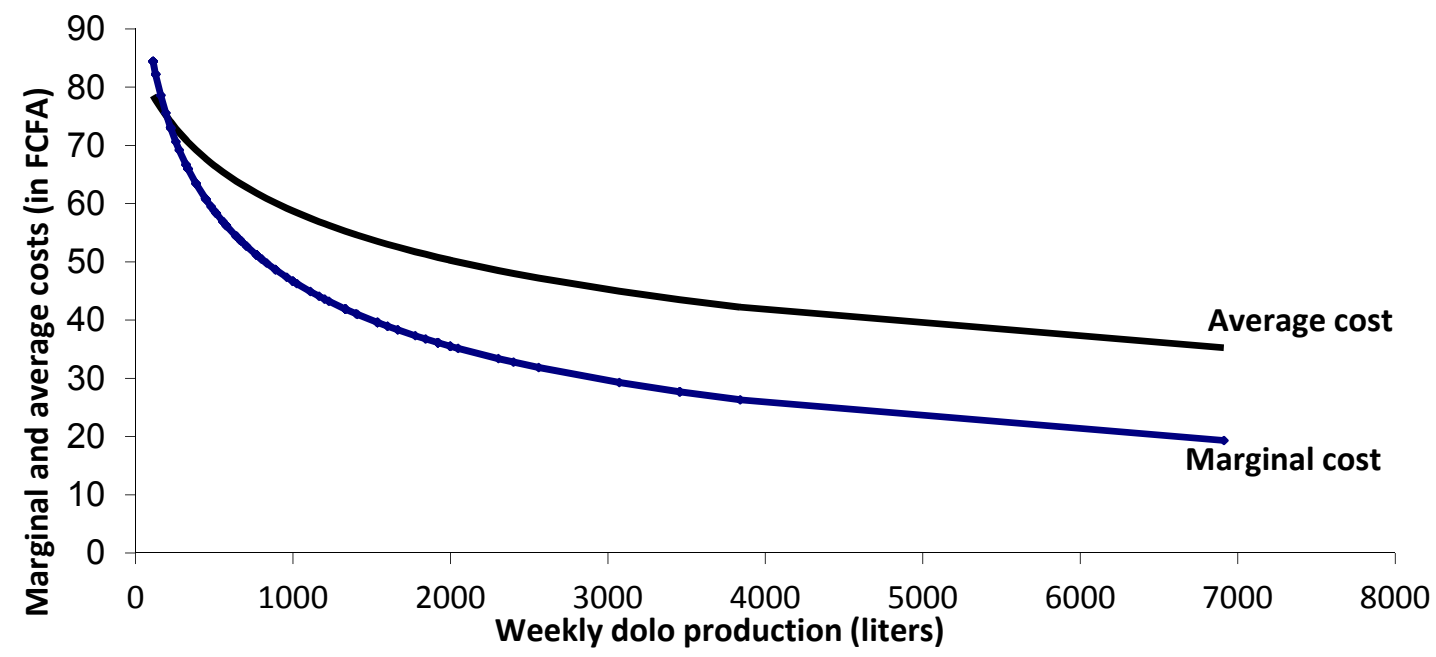

Figure 4. Marginal and mean costs of dolo production (setting inputs prices to sample average)

Marginal cost is a decreasing function of the production. This does confirm the existence of the previously identified increasing return to scale.

We have computed marginal costs relating to each "dolotière" $k$ considering input prices that each of them faces.

The formula used is then:

$$
\begin{aligned}
& C m V M_{k}=\frac{\partial C T V M_{k}}{\partial Y_{k}}=-\frac{e^{b_{k}}}{\bar{Y}^{c_{k}}}\left[2 \gamma_{Y Y} \ln (\bar{Y})-c_{k}-2 \gamma_{Y Y} \ln \left(Y_{k}\right)\right] Y_{k}^{\left(c_{k}-1\right)} e^{\gamma_{Y Y}\left[\ln (\bar{Y})-\ln \left(Y_{k}\right)\right]^{2}}, \text { avec } \\
& b_{k}=\alpha_{y}+\sum_{i} \gamma_{i Y} \ln \left(\frac{P_{i k}}{\bar{P}_{i}}\right) \text { et } c_{k}=\ln \alpha_{0}+\sum_{i=1}^{n} \alpha_{i} \ln \left(\frac{P_{i k}}{\bar{P}_{i}}\right)
\end{aligned}
$$

Graph 5 shows marginal costs distribution according to production level. 


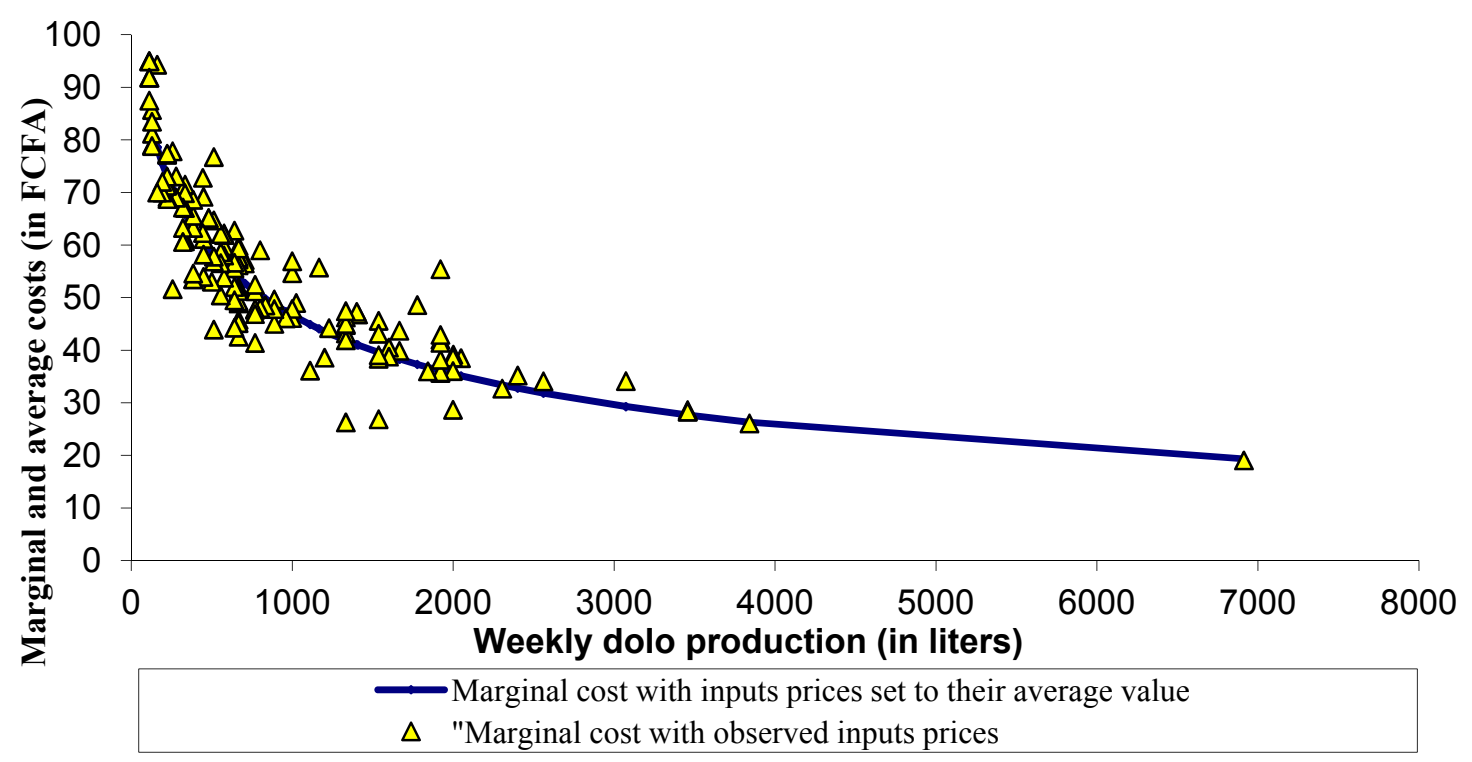

Figure 5. Estimated and trend of marginal costs of dolo production (setting prices to sample average)

\subsubsection{Technical Substitution Elasticities}

Allen's partial substitution elasticities allow to measure technical substitution between factors of production. These crossed between one another indicate which ones are substitutable or complementary. A positive (negative) value of $\sigma_{i j}$ implies that factors $i$ and $j$ are substitutable (complementary); if $\sigma_{i j}=0$, then the two factors are independent (Field and Berndt, 1981, p. 55). These elasticities are computed through the following formula:

$$
\begin{gathered}
\sigma_{i j}=\frac{\gamma_{i j}+S_{i} S_{j}}{S_{i} S_{j}}, \quad i, j=1, \ldots, n, \quad \text { mais } i \neq j \\
\sigma_{i i}=\frac{\gamma_{i i}+S_{i}^{2}-S_{i}}{S_{i}^{2}}, \quad i=1, \ldots, n \text { avec } i=j
\end{gathered}
$$

$\gamma_{\mathrm{ij}}, \gamma_{\mathrm{ii}}, \mathrm{S}_{\mathrm{i}}, \mathrm{S}_{\mathrm{j}}$ are respectively coefficients of factors prices, and cost shares of different factors in the production.

\begin{tabular}{|c|c|c|c|c|}
\hline & \multicolumn{2}{|c|}{ Firewood Red Sorghum } & Water & Labor \\
\hline Fuelwood & $-0,8021$ & & & \\
\hline Red Sorghum & 0,1004 & $-\mathbf{0 , 1 2 7 7}$ & & \\
\hline Labor & 0,0023 & $-0,0004$ & $-4,8037$ & \\
\hline Water & 0,0021 & $-0,0012$ & 0,0000 & $-0,1506$ \\
\hline
\end{tabular}

Table 3. Allen's partial technical substitution elasticities

Germinated millet, water and labor appear weakly substitutable to firewood. We observe a complementarity between germinated millet and water, and between germinated millet and labor.

\subsubsection{Input Price-Elasticities}

Direct and cross price-elasticities of input conditional demand are given by the following formula: 


$$
\begin{gathered}
\varepsilon_{i j}=\frac{\gamma_{i j}+S_{i} S_{j}}{S_{i}}, \quad i=1, \ldots ., n, \text { avec } i \neq j \\
\varepsilon_{i i}=\frac{\gamma_{i i}+S_{i}^{2}-S_{i}}{S_{i}}, \quad i=1, \ldots ., n, \text { avec } i=j
\end{gathered}
$$

A given factor demand sensitivity to changes occurring in its own price is measured thanks to direct price-elasticities. Existing economic relation between factors is quantified by cross price-elasticities.

\begin{tabular}{|c|c|c|c|c|}
\hline & Firewood & Red Sorghum & Water & Labor \\
\hline Firewood & -0.26241 & & & \\
\hline Red Sorghum & 0.17672 & -0.07257 & & \\
\hline Labor & 0.04845 & -0.00864 & -0.22905 & \\
\hline Water & 0.03723 & -0.02054 & -0.00047 & -0.00857 \\
\hline
\end{tabular}

Table 4. Input demands price-elasticities

From all factors, firewood is the most responsive to its own price. A $1 \%$ increase of its price induces a $0.26 \%$ decrease in its demand. We find that geminated millet of which the cost share is prevailing is found to have a relatively low own price elasticity $(0.07 \%)$. Cross-price elasticities with firewood are positive, the highest being the one between firewood and germinated millet. A price increase of these factors leads to an increased demand for firewood. As for sprouted millet, its technical substitutability with firewood, observed above, is legitimated. For the other two factors, we keep commenting the figures due to their very low coefficients.

\subsection{Results for Dolo Production Industry in Ouagadougou}

\subsubsection{Supply Function of Dolo}

Total production per week of the surveyed sample is 142,021 liters for the 149 "dolotières". The sampling procedure allows us to assume these samples as representative. We can then estimate the total production of dolo for the city of Ouagadougou provided by the 1013 "dolotières" to: $142021 \times(1013 / 149)=965550$ liters. To establish the supply curve, we aggregate the productions according to the level of marginal cost by assigning each sample production the multiplicative coefficient of that one (1013/149). Graph No. 6 restores the supply curve.

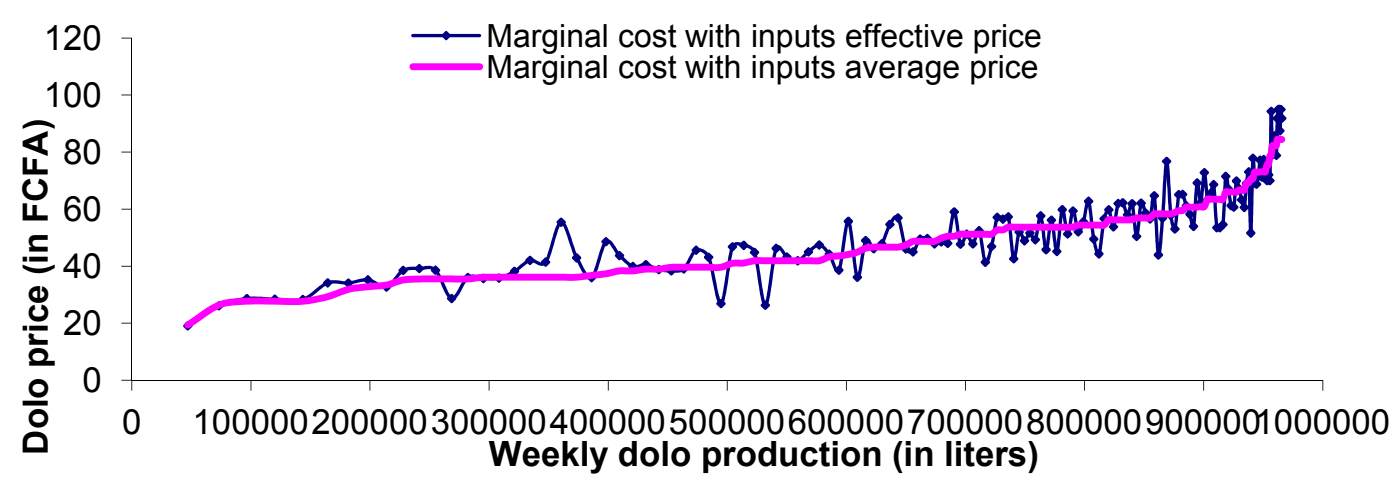

Figure 6. Dolo weekly supply curve

A review of producers' staff according to their production capacity shows that a relatively small number of "dolotières" provides a very significant share of production. Graph No. 7 describes this situation. 


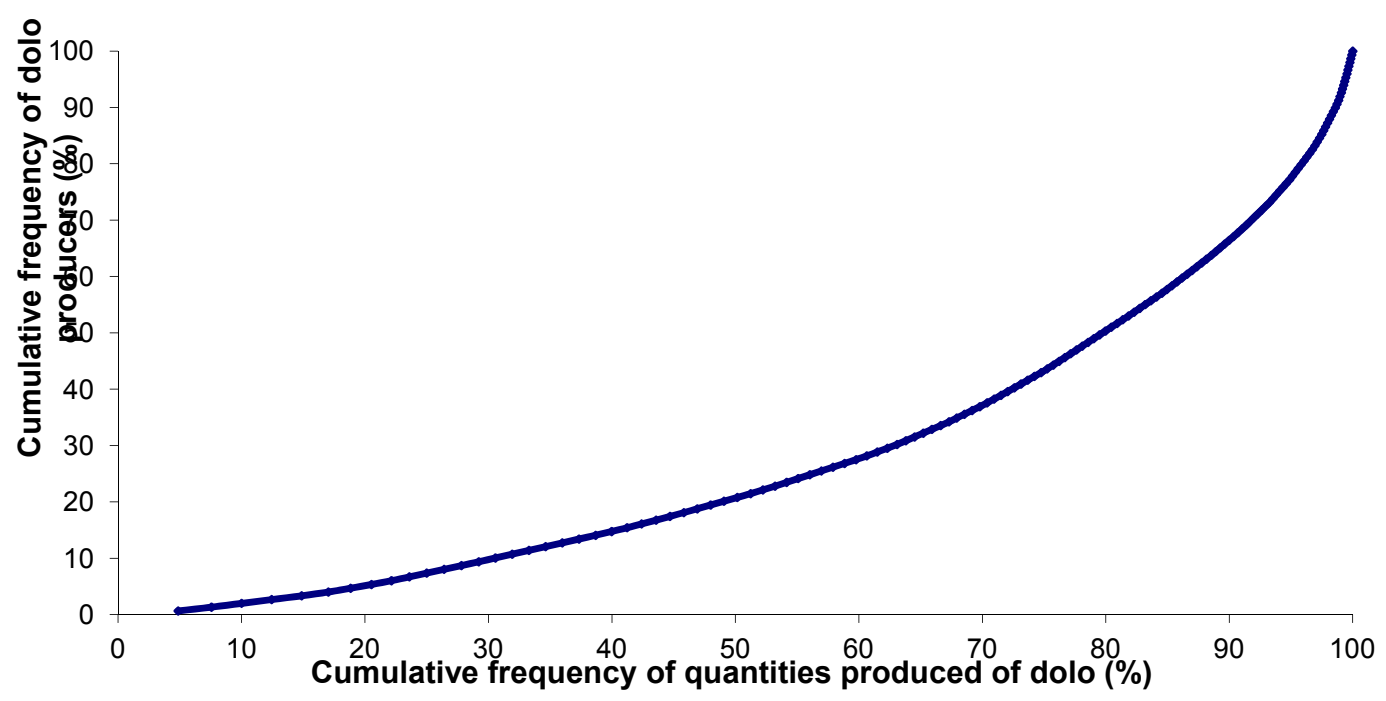

Figure 7. Concentration of dolo production's activity

We remark that $50 \%$ of production is provided by $20 \%$ of "dolotières", and that $50 \%$ of "dolotières" supply $80 \%$ of the market. This relative concentration is to be taken into account in any policy designed to promote a reduced use of firewood.

\subsubsection{Dolo Producers' Total Surplus}

The price per liter of dolo is uniform over the city of Ouagadougou. It is 100 CFA Franc (Note 4). Examination of the supply curve and the level of price 100 CFA F show the producer surplus. To the extent that we do not have individualized information on fixed costs, we will not calculate the profit, but producer surplus which is the difference between their turnover and their variable total cost.

Here, the total surplus per week establishes at 42.09 million of CFA Franc. That is, 2,188.72 million of CFA F per year. It is found that this activity is highly profitable.

Graph 8 shows the evolution of total producer's surplus as a function of total production.

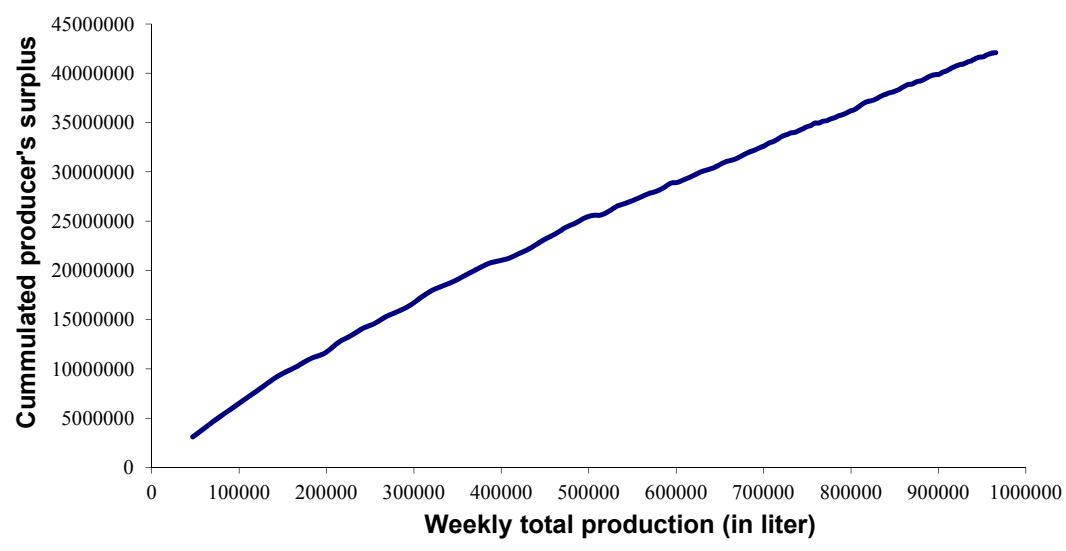

Figure 8. Trend of cumulated producers's surplus as a function of dolo total production

Production concentration, as above observed, add to the existence of economy returns of scale contribute to magnify concentration in producers' surplus mobilization. 


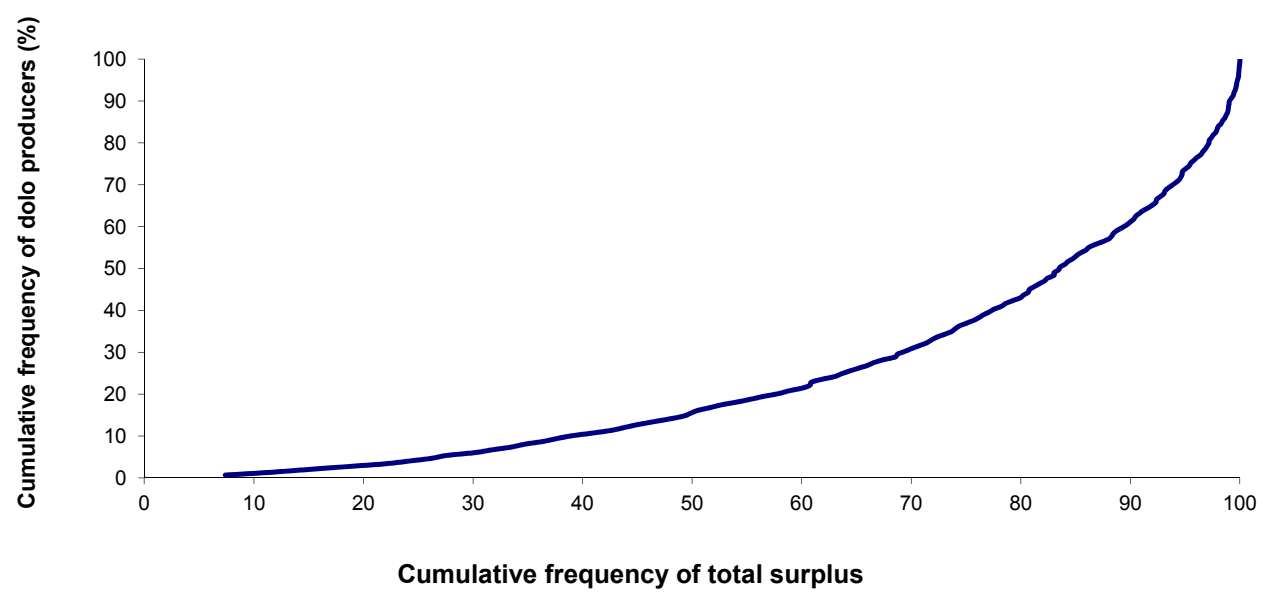

Figure 9. Concentration of total surplus between dolo producers

Graph $\mathrm{N}^{\circ} 9$ reveals that almost $60 \%$ of the total surplus is mobilized by $20 \%$ of producers.

4.3.3 Firewood Demand for Dolo Production

Shepard's lemma allows getting directly conditional demand functions from cost function. As for firewood, we get:

$$
Q_{B}\left(P_{B}, P_{M}, P_{E}, P_{L}, Y\right)=\frac{\partial C T V\left(P_{B}, P_{M}, P_{E}, P_{L}, Y\right)}{\partial P_{B}}
$$

Fixing values, excepted wood price to sample average, induces variable total cost to become:

$$
\ln (C T V)=\ln \left(\alpha_{0}\right)+\alpha_{B} \ln \left(\frac{P_{B}}{\bar{P}_{B}}\right)+1 / 2 \alpha_{B B}\left[\ln \left(\frac{P_{B}}{\bar{P}_{B}}\right)\right]^{2}
$$

Or:

$$
\begin{gathered}
\left.C T V=e^{\alpha_{0}}\left(\frac{P_{B}}{\bar{P}_{B}}\right)^{\alpha_{B}} e^{\left[1 / 2 \alpha_{B B}\left(\ln \frac{P_{B}}{\bar{P}_{B}}\right)^{2}\right]}\right] \\
\frac{\partial C T V}{\partial P_{B}}=\left(\frac{e^{\alpha_{0}}}{\bar{P}_{B}^{\alpha_{B}}}\right)\left(\alpha_{B}-\alpha_{B B} \ln \left(\frac{P_{B}}{\bar{P}_{B}}\right)\right) P_{B}^{\left(\alpha_{B}-1\right)} e^{1 / 2 \alpha_{B B}\left(\ln \left(\frac{P_{B}}{\bar{P}_{B}}\right)^{2}\right.}
\end{gathered}
$$

Relying on firewood prices paid by "dolotières" in the sample, we can plot demand function derived from millet beer production wood as in graph no. 10 . 


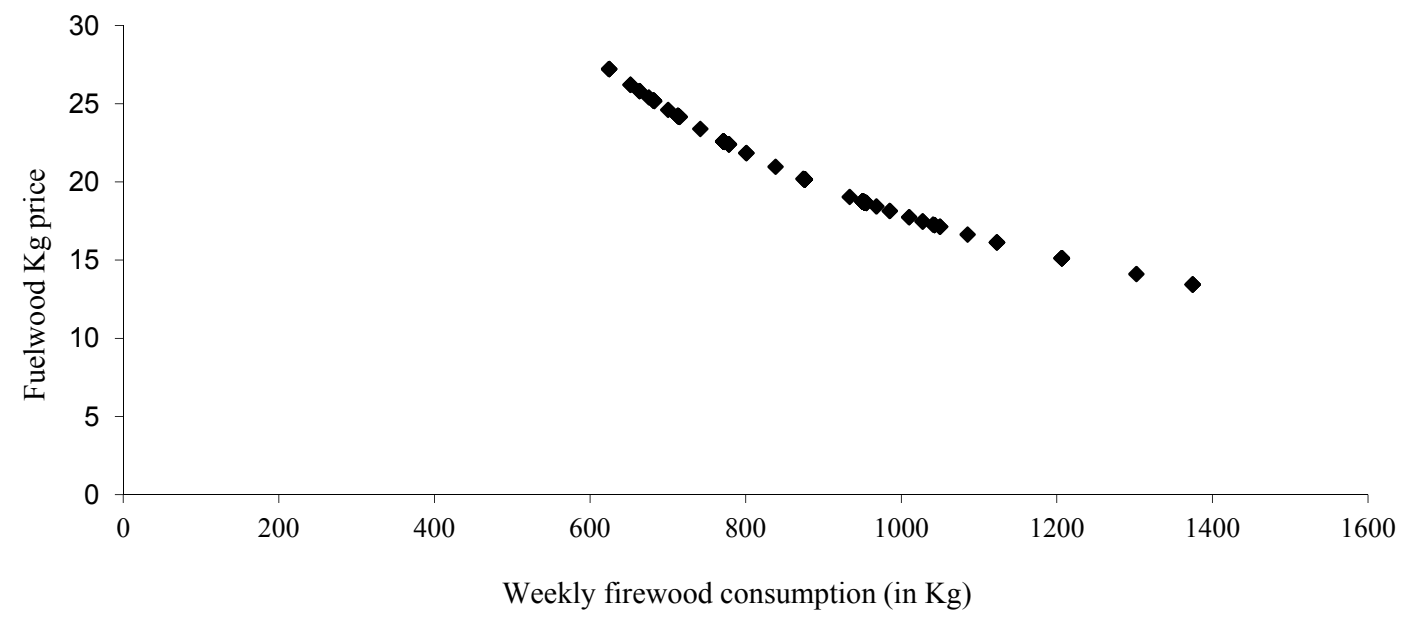

Figure 10. Firewood demand for dolo production

Examination of direct-price elasticity for firewood $\varepsilon_{\mathrm{BB}}=-0,262$ confirms that firewood demand is not rigid, even though this value is quite low.

\subsection{Simulations for a Lower Usage of Firewood in Dolo Production}

We will develop only analyses with regard to actions regarding variable factors. This should be supplemented by a combined action on the fixed factors.

\subsubsection{Effects of an Environmental Levy on Firewood Demand}

To restore a proper pricing of the resource and to get virtuous results in saving resource, in alternating source of energy and in incentivizing an increase of supply, it is often advised to build on taxation through the re-adjustment of existing taxes or charges, or by creating new taxes.

It is known that the price of the standing resource is on average very low and often below the cost of rebuilding the resource. A study of firewood price structure sold at retail shows that the share of taxes related to the resource itself (environmental taxes and charges related to the regulation of uses) represents $20.4 \%$ of the price. The effectiveness of this tax is problematic, particularly with regard to environmental taxes. Arguably, 1,167,610 cubic meters get beyond environmental taxes. That is, a loss of 1.051 billion CFA francs. This represents a percentage of $85 \%$ of tax avoidance. Since the industry supplying "dolotières" uses large motorized transport (trucks with a capacity of 12 to 35 cubic meter of wood) sourcing generally in arranged and controlled timber yards, it is assumed that the degree of avoidance is lower than the observed one throughout firewood sector in Ouagadougou, and this rate of avoidance is at an average level of about $50 \%$ for the sector affecting "dolotières".

Hypothesis:

Tax avoidance $=50 \%$

Eco tax $=20.4 \%$.

If there is more evasion, the average price is $\times 2$.

$\mathrm{p}$ the price of firewood

$\mathrm{H}$ the percentage increase

$\mathrm{H} \times 0.204 \times 2 \mathrm{p}=1.25 \mathrm{p}$, equally $\mathrm{h}=1.25 / 0.204 \times 2=3$

A multiplier coefficient of 3 , associated with a general implementation led to an increase in retail prices of wood by $25 \%$.

We will show what effects of such an increase are on firewood consumption for dolo production, on dolo production itself and on producers. 
Conditional demand for timber factor will be modified by the reassessed price of wood. Starting from demand function derived from equation 17 , we can draw the new profile.

The movement of wood demand curve resulting from changing of wood supply conditions (charging the price at $25 \%$ ) is given by graph 11 .

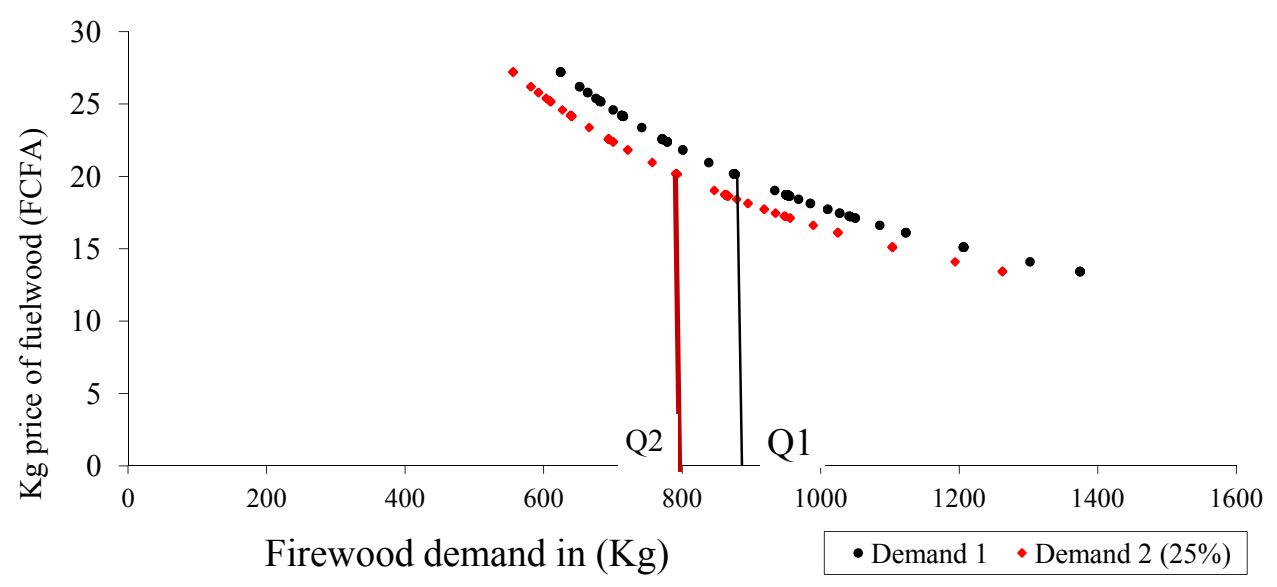

Figure 11. Effects of firewood demand of an environmental levy of $25 \%$ on firewood prices

This is achieved by assuming that the prices of all other factors are fixed at their average. We clearly observe a downward shift of the derived demand for wood, meaning that for the same price level the quantity demanded of firewood is always less on disturbed demand than on the initial one. For the same price level, the quantity required from the disturbed demand curve is always less than that of the original demand curve $(\mathrm{Q} 2<\mathrm{Q} 1)$.

We will more accurately calculate the change in quantity consumed, considering the factor price for each producer. The introduction of a $25 \%$ tax on timber prices will generate on average and by "dolotière" a weekly decline in quantity demanded of firewood of $85 \mathrm{~kg}$, representing dolotière's weekly saving of wood generated. On a global scale of all "dolotières" of this town, an annual saving of firewood resulting from this tax will be around a volume of 4,915 tons of firewood.

\subsubsection{Effects of an Environmental Levy on Dolo Production}

Chart No. 12 shows the movement direction of the aggregate supply curve by dolotières following a rise in firewood price $25 \%$.

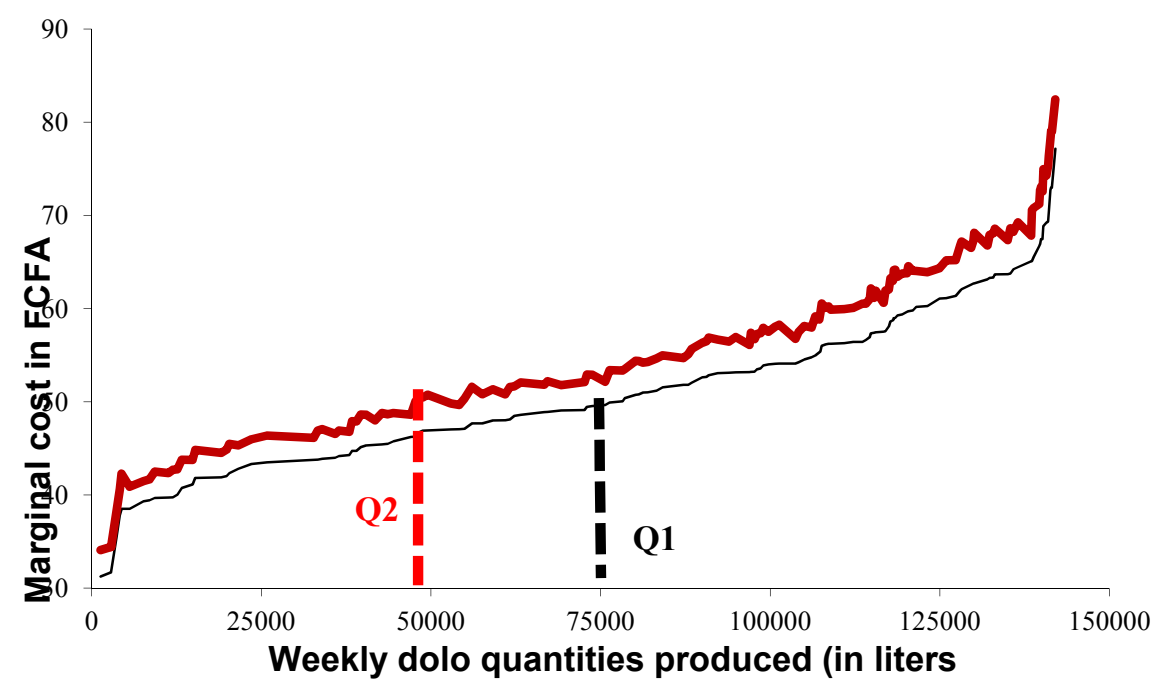

Figure 12. Effects of an environmental levy on dolo total supply in Ouagadougou 
Rising timber prices will lead to a change in dolo supply conditions. The rising of firewood price will cause an upward movement of the supply curve to reflect naturally the increase in marginal cost due to this price increase. This upward shift of the aggregate supply curve represents a drop in dolotière's profit, since for a given level of output, marginal cost is higher for supply curve 2 (Offer 2). This decrease in the dolotière's profit reflects a loss of dolotière's production surplus due to firewood high price.

The annual loss of production surplus resulting from this $25 \%$ price increase for all dolotières is given by the following formula:

$\Delta \mathrm{SP}=\Sigma$ Initial production surplus $-\Sigma$ Production surplus with rising prices

$$
\begin{aligned}
\Delta \mathrm{SP}= & (6,191,047 \text { CFA F }-5570158.5 \text { CFA F }) \times(1013 / 149) \times 52 \\
& =620888.5 \text { CFA F } \times(1013 / 149) \times 52=219502836 \text { CFA Franc. }
\end{aligned}
$$

An annual loss of production surplus of about CFA F 219502836 will be due to this price increase, for an annual production level of 50,208,713 liters of dolo produced by the whole industry in this city. This decline of surplus will result in a medium and long term decrease in dolo production and therefore, a lower demand for firewood. For the same level of marginal cost, production level of the sector will always fall behind the initial one after the price increase $(\mathrm{Q} 2<\mathrm{Q} 1)$. This increase could also result for dolotières in coping behaviors through saving attitudes and efficiency in energy usage, or through increases in dolo cost to offset the loss of surplus. In the latter case, it is the consumer who will pay the firewood higher price.

\section{Conclusion}

This work estimated the cost function and derived the conditional inputs' demands of the local red sorghum beer production in Ouagadougou. The calculation of inputs' technical substitution elasticities helped to highlight the technical characteristics of this activity. These elasticities show a low substitutability of other inputs to firewood. Thus, they highlight complementary links between water and firewood on the one hand, so for labor and firewood on the other.

The analysis of the relationship between the dolo production share costs and quantity produced shows a decline in firewood share cost when the quantities produced increase. The results predict increasing returns to scale for this activity. The formula Giora Hanoch (1975) has highlighted a dolo production technology with increasing returns to scale with a coefficient equal to 1.25 performance.

Studying the concentration of dolo production and producers' surplus among dolotières reveals a pronounced inequality in the distribution of production and surplus. While $50 \%$ of production is provided by $20 \%$ of dolotières, $60 \%$ of the total surplus amounts to $20 \%$ of producers. There exists a few large dolotières who produce only for wholesalers account for the largest share of the surplus. This concentration of dolo production and its surplus among producers is a major asset for any policy to reduce the consumption of firewood.

This paper also stated the economy of wood energy and the loss of dolo producers' surplus induced by an environmental levy on wood energy. This results in an annual saving of 4,915 tons of workable wood energy on this activity with an annual decline of dolotières total surplus of about 219,502,836 FCFA.

Craft industry, user of firewood as input, represents $59 \%$ of total demand in Ouagadougou and includes a limited number of operators (about 10,000), and as such, should be a prime target for policy regarding demand for firewood management. Given the price inelastic craft demand for firewood observed and the lack of real alternatives, a pure tax policy would not be effective. On the other hand, support for suitable equipment (Note 5) establishment might be effective. One could imagine a system like the one adopted by water agencies in France. It collects charges on craftsmen, and it uses the amount of these fees to subsidize the acquisition of better equipment and / or training craftsmen on techniques or processes of production more efficient in terms of wood consumption. This could be implemented by a specialized agency that would manage a fund from fees and redistribute according to the development of projects that would get real savings on firewood. Such a specialized agency could be the Applied Sciences and Technology Research Institute (Note 6) (IRSAT). The I.R.S.A.T., indeed, is the best suited institute for such an operation since it has available skills at its disposal in this area to propose or evaluate technically and economically feasible projects thereto. It might require some financial contribution to the beneficiaries. "Dolotières" should be a pilot class of artisans for testing such an operation or policy with regard to the importance of their consumption coefficient.

\section{References}

Anderson, D. (1996). Energie et environnement: Possibilités techniques et économiques. Revue Finances \& Développement: Paris. 
Babin, G. F., Willis, C. E., \& Allen, P. G. (1982). Estimation of Substitution Possibilities between Water and Other Production Inputs, American Agricultural Economics Association, USA.

Berndt, E. (1991). The practice of econometrics: Classic and contemporary, Addison-Wesley Publishing Company, Reading.

Berndt, E., \& Christensen, L. R. (1973). The translog function and the substitution of equipment, structures and labor in U.S. manufacturing, 1929-1968. Journal of Econometrics, 1, 81-363. http://dx.doi.org/10.1016/0304-4076(73)90007-9

Bousquet, A., \& Ivaldi, M. (1998). An individual choice model of energy mix. Resource and Energy Economics (pp. 263-286). Santa Barabara,

Garcia, S. (2002). Rendements et efficacité dans les industries en réseau: le cas des services d'eau potable délégués. Economie \& Prévision, 154(3), 123-138.

Grebenstein, C. R., \& Field, B. C. (1979). Substitution for Water Inputs in U.S. Manufacturing. Water Resources Research, 15(2), 228-232, New York. http://dx.doi.org/10.1029/WR015i002p00228

Greene, H. W. (1993). Econometric Analysis, Macmillan Publishing Company; New York, USA.

Mas-Colell, A., Whinston, M. D., \& Green, J. R. (1995). Microeconomic theory, Oxford University Press. New York.

Mcelroy, M. B. (1987). Additive error models for production, cost and derived demand of share system. Journal of Politic Economics, 95, 737-757. http://dx.doi.org/10.1086/261483

Naief, A. M., \& Nadeem, A. B. (2002). Factor substitution, and economies of scale and utilisation in Kuwait'scrude oil industry. Energy Economics, 24, Elsevier, Pages 337-354, North-Holland.

Ouedraogo, B. (2002). Eléments Économiques pour la Gestion de l'Offre et de la Demande du Bois-énergie dans la région de. Thèse de Doctorat Unique, Université de Ouagadougou \& Université Montesquieu-Bordeaux IV.

Ouedraogo, M. M. (1974). L'Approvisionnement de Ouagadougou en Produits Vivriers, en Eau et en Bois., Thèse de Doctorat de $3^{\circ}$ Cycle, C.V.R.S.: Université Bordeaux III. 353 pages.

Panayotou, T., \& Sungsuwan, S. (1996). An econometric analysis of the causes of tropical deforestation: The case of Nordeast Thailand. In K. Brown, \& D. W. PEARCE (Eds.), The Causes of Tropical Deforestation (pp. 192-210). ULC Press. London.

RPTES (mai 2000). Demande Artisanale du bois-énergie comme Facteur de Production: cas des dolotières, restaurateurs, grilleurs de viande, fondeurs de bronze et d'aluminium, Ouagadougou.

Sadoulet, E., \& De, J. A., (1995). Quantitative Development Policy Analysis. The Johns Hopkins Press Ltd, London.

Teeples, R., \& Glyer, D. (1987). Production Functions for Water Delivery Systems: Analysis and Estimation Using Dual Cost Function and Implicit Piece Specification. Water Resources Research, 23(5), 765-773, California. http://dx.doi.org/10.1029/WR023i005p00765

Urga, G., \& Walters, C. (2003). Dynamic translog and linear logit models :a factor demand analysis of interfuel substitution in US industrial energy demand. Energy Economics, 25(I), 1-21, Elsevier. http://dx.doi.org/10.1016/S0140-9883(02)00022-1

Wooldridge, J. M. (2000). Introductory Econometrics: A Modern Approach, South-Western College Publishing, Michigan State University.

Zellner, A. (1962). An Efficient Method of Estimating Seemingly Unrelated Regression and Tests for aggregation Bias. Journal of the American Statistical Association, 57, 348-368. http://dx.doi.org/10.1080/01621459.1962.10480664

\section{Notes}

Note 1. Many studies related to water and telecommunication manufacture industries demand for energy in the United States, have used translog as functional form [Hudson and Jorgenson (1974), Berndt and Wood (1975), Christensen and Green (1975), Berndt and Khaled (1979), Berndt and Morrison (1979), C. R. Grebenstein and B. C. Field (1979), Anderson (1980), Berndt et al. (1981), Evans and Heckman (1984), R. Teeples and D. Glyer 
(1987), Berndt (1991) and Garcia S. (2002)].

Note 2. Equation (1) is the most general and flexible cost function specification which can be used to test diverse restrictions on production structure such as homotheticity, homogeneity, substitution possibilities, etc.

Note 3. Recall that the term $Y Y=0$ and that as such YY.lnY $=0$ in the elasticity expression.

Note 4. In reality, dolo is consumed per calabash.

Note 5. Nonetheless, one should note that reducing cooking time and / or achieving savings on fuelwood could come from artisans' production processes. Our thought is directed toward the specific case of "dolotières" where research has revealed the possibility of reducing quite considerably the cooking time or preparation time while obtaining the best beer.

Note 6. Applied Sciences and Technology Research Institute (IRSAT) is the former "Burkinabé Institute of Energy" which has already experienced the adaptation of gas fireplaces and studied yields on improved stoves with firewood.

\section{Copyrights}

Copyright for this article is retained by the author(s), with first publication rights granted to the journal.

This is an open-access article distributed under the terms and conditions of the Creative Commons Attribution license (http://creativecommons.org/licenses/by/3.0/). 